\title{
Dinosaur tracks from Tang Dynasty Grottoes area in Sichuan
}

\section{Province, China}

\author{
Lida Xing a, b ${ }^{*}$, Martin G. Lockley ${ }^{c}$, Zheng Ren $^{b}$, Chang Liu ${ }^{b}$, W. Scott Persons IV d, Guangzhao Peng ${ }^{e}$, \\ Yong Ye ${ }^{e}$, Shan Jiang ${ }^{e}$ \\ a State Key Laboratory of Biogeology and Environmental Geology, China University of Geosciences, \\ Beijing, 100083, China \\ ${ }^{b}$ School of the Earth Sciences and Resources, China University of Geosciences, Beijing, 100083, China \\ c Dinosaur Trackers Research Group, University of Colorado, Denver 80217, USA \\ ${ }^{d}$ Mace Brown Museum of Natural History, Department of Geology and Environmental Geosciences, \\ College of Charleston, Charleston 29401, USA \\ e Zigong Dinosaur Museum, Zigong, China \\ *Corresponding author. Lida Xing: xinglida@gmail.com
}

(C) The Authors, 2021

\begin{abstract}
In recent year the number of tracksites discovered and reported from the Lower Cretaceous Jiaguan Formation, Sichuan Basin has increased steadily. Here we report on the $20^{\text {th }}$ and $21^{\text {st }}$ sites which are situated in unusual locations in a cave and on a steep bedding plane surface in association with Tang Dynasty grottoes. The ichnofauna is represented by two small assemblages which are both theropod-dominated. Due to sub-optimal preservation, the tracks are identified only as grallatorid and small and larger eubrontid, with Paracorpulentapus also tentatively recognized.
\end{abstract}

\section{ARTICLE HISTORY}

Received: 8-02-2021

Revised: 20-02-2021

Accepted: 20-03-2021

\section{KEYWORDS}

Theropod tracks

Grallatorid

Eubrontid

Paracorpulentapus

\section{Introduction}

In the Sichuan Basin, the Lower Cretaceous Jiaguan Formation is a typical Type 1 or Type 2 ichnofaunal deposits, with the dinosaur fossil record consisting only of tracks or being dominated by tracks (Xing et al., 2018a). Many dense tracksites record a taxonomic diversity of avian and non-avian theropods, sauropods, ornithopods, possible thyreophorans, and pterosaurs (Xing \& Lockley, 2016). This rich track record has permitted detailed study of the Jiaguan Formation's dinosaur fauna (Xing et al., 2016).

Xing and Lockley (2016) and Xing et al. (in review) described 18 track sites from the Jiaguan Formation. The 19th track site, the Changtan site, is geographically close to the $18^{\text {th }}$ and is currently under study. More than $80 \%$ of these Jiaguan Formation tracksites are in the southeastern part of the Sichuan Basin, and are concentrated in the Qijiang-Gulin area. In the west of the basin, a few sites have been discovered, such as the Emei (Chuanzhu) and Huibu sites (Xing et al., 2018b). In January 2020, YAN Zongmi, a geological team member from Sichuan, reported to the first author the location of several dinosaur footprints from Qianfoyan, Jiajiang County, Leshan City, in the western Sichuan Basin (Fig 1). These new records became the 20th and 21th track sites of the Jiaguan Formation: Lingyadong site or Lingya cave site (GPS: N 29० 45' 16", E $\left.103^{\circ} 32^{\prime} 21^{\prime \prime}\right)$ and Qianfoyan site (GPS: N 29० $45^{\prime} 14^{\prime \prime}$, E $103^{\circ} 32^{\prime}$ 58") (Fig 2). The former tracksite lies $1 \mathrm{~km}$ straight west of the latter. 


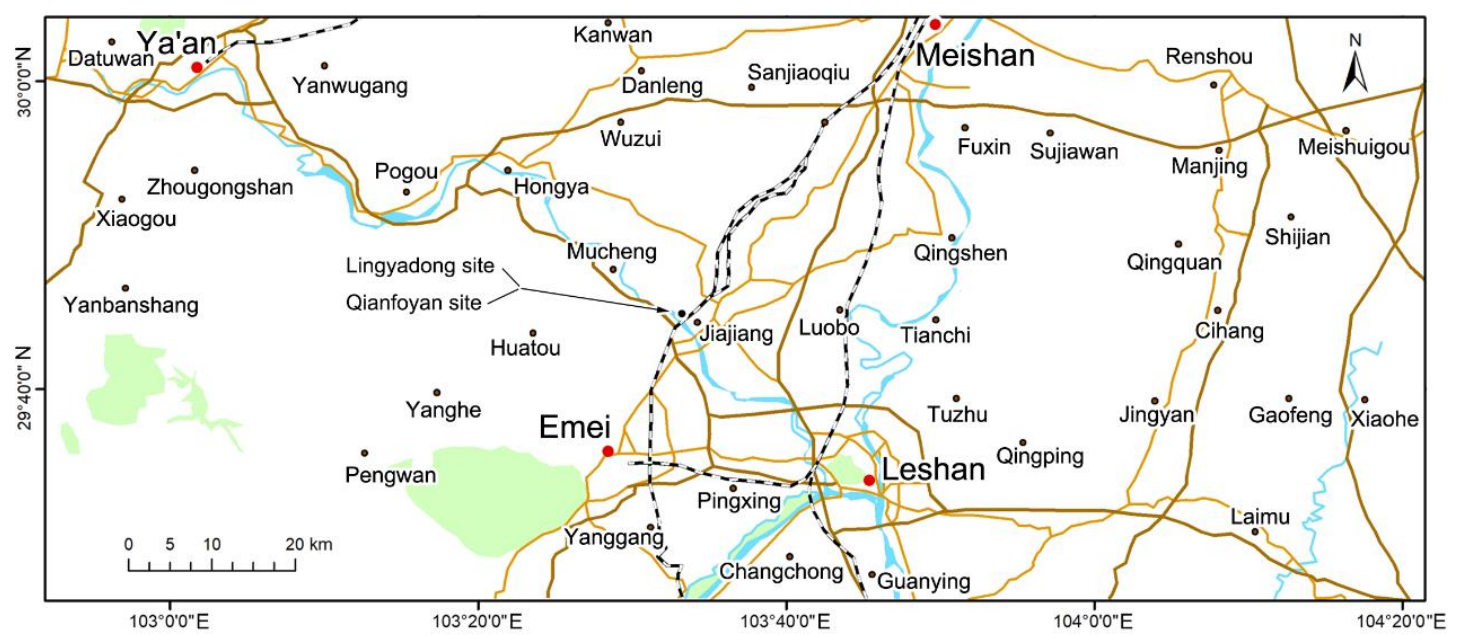

Figure 1. Geographical setting showing the location of the Lingyadong and Qianfoyan sites in Sichuan Province, China.

The two new tracksites are both on Qianfoyan, or Qianfo Cliff, which means "a rock with thousands of Buddha sculptures". Qianfoyan is located at Daguan mountain, along the Qingyi River in Jiajiang County (Yu \& Wang, 2012). With a temperate subtropical climate, the area is 380 to 820 meters above sea level and covers an area of about $4.5 \mathrm{~km}^{2}$. The Qianfoyan Buddha statues were carved in the Tang Dynasty (A.D. 618-907), Ming Dynasty (A.D. 1368-1644), and Qing Dynasty (A.D. 1636-1912) (Liang, 2011; Yu \& Wang, 2012). The statues are densely distributed on the steep cliff, facing the river, across a cliff surface roughly $60 \mathrm{~m}$ tall and $600 \mathrm{~m}$ long, including 162 caves. More than 2,470 stone statues are present (Yu \& Wang, 2012). In 2006, Qianfoyan was included in the sixth batch of historic protected sites (Major Historical and Cultural Site Protected at the National Level, No. VI 85) (National Administration of Cultural Heritage, 2009). No inscriptions or written record were found in the cave at the Lingyadong site, making the exact date of its excavation is uncertain. The Lingyadong site may have served as a warehouse or as a living space for resident Buddhists.

\section{Materials and methods}

Lingyadong site is inside the Jiajiang Qianfoyan Scenic Spot (Fig 3). The Lingya cave is $3 \mathrm{~m}$ in height, $2.5 \mathrm{~m}$ in width, and $40 \mathrm{~m}$ in deep. The tracks are located on the top siltstone surface at the end of the cave, which is about $2-3 \mathrm{~m}^{2}$. Also present on this surface are well-developed ripple marks. There are eight footprints in total, all of which are natural casts. Three comprise a distinct trackway (cataloged as LYD-T1) and five are isolated tracks (cataloged as LYD-T11-5. The authors outlined the tracks with chalk, and measured and photographed them.
Qianfoyan site is located on a steep rock face in the parking lot at the entrance of the scenic spot and is currently a construction site for an apartment complex (Fig 4). The track bearing rock face is about $25 \mathrm{~m}$ tall. There are two track areas exposed on the siltstone surfaces. Area 1 is about $7 \mathrm{~m}$ above the ground, and consists of two footprints (cataloged as QFY-T1-L1 and R1) that form a single step (Fig 5). Area 2 is about $14 \mathrm{~m}$ above the ground, with well-developed ripple marks and invertebrate traces. The 8 footprints are cataloged as QFY-TI1-8 (Fig 6). Area 1 is approximately $1.5 \mathrm{~m}$ higher than Area 2 in the sedimentary sequence.

Due to the steepness of the bedding planes $\left(80^{\circ}\right)$ at Qianfoyan tracksite, it was necessary to use safety ropes during the study. Professional mountaineers set up natural anchors at the top of the mountain, descended to Areas 1 and 2 by ropes, cleaned the plants near the tracks, drew the outline of the tracks with chalks, and, following the standard procedures of Leonardi (1987) and Lockley and Hunt (1995), measured the following data: maximum Length (L), maximum width (W), pace length (PL), stride length (SL), and track rotation (R). All footprints were photographed, and some of the well-preserved footprints were traced onto sheets of transparent plastics. No natural casts were collected.

The whole exposed surface was photographically recorded using a remote controlled four axis quadcopter (DJI Phantom 4 Pro: weight: $1388 \mathrm{~g}$; max service ceiling above sea level: $6000 \mathrm{~m}$; max flight time: $30 \mathrm{~min}$; max wind speed resistance: $10 \mathrm{~m} / \mathrm{s}$ and with DJI GO App, iOS 8.0 or later) with a 20 million effective pixels camera (FC6310, with an $8.8 \mathrm{~mm} / 24 \mathrm{~mm}$ lens, f/2.8 $\mathrm{f} / 11)$. After taking off from the ground, the DJI Phantom 4 Pro was controlled remotely and it 
provide real-time HD video through a mobile APP (DJI GO 4).

\section{Geological setting}

The local Cretaceous sedimentary sequences are composed of the Jiaguan Formation (Lower Cretaceous) and the Guankou Formation (Upper Cretaceous) (Gu \& Liu, 1997). The Jiaguan Formation is characterized by thick, brick red, feldspathic, quartz sandstones (Sichuan Provincial Bureau of Geology aviation regional Geological Survey team 1976) (Fig 2). The main authors of this paper have described in detail the lithostratigraphy and geochronology of the Jiaguan Formation in previous papers (such as Xing et al., 2016).

Qianfoyan is $30 \mathrm{~km}$ away from the Leshan Giant
Buddha (Leshan Giant Buddha Scenic Area, A.D. 713), which has been listed as a UNESCO World Heritage Site since 1996. They are both located in the Upper Member of the Jiaguan Formation, which is a thick, purplish, sandstone body (He, 2010). From an engineering point of view, this rock very suitable for the excavation of caves and carving of cliff figures.

The Upper Member of the Jiaguan Formation is 345-1000 $\mathrm{m}$ thick and is comprised of feldspathic quartz sandstone interbedded with thin layers of lenticular mudstone and siltstone. The sediments of the Jiaguan Formation are those of alluvial fan, river and desert deposits (Geng, 2011). Chen (2009) argued that the Upper Member represents a meandering stream deposit interbedded with deposition from small, braided rivers.

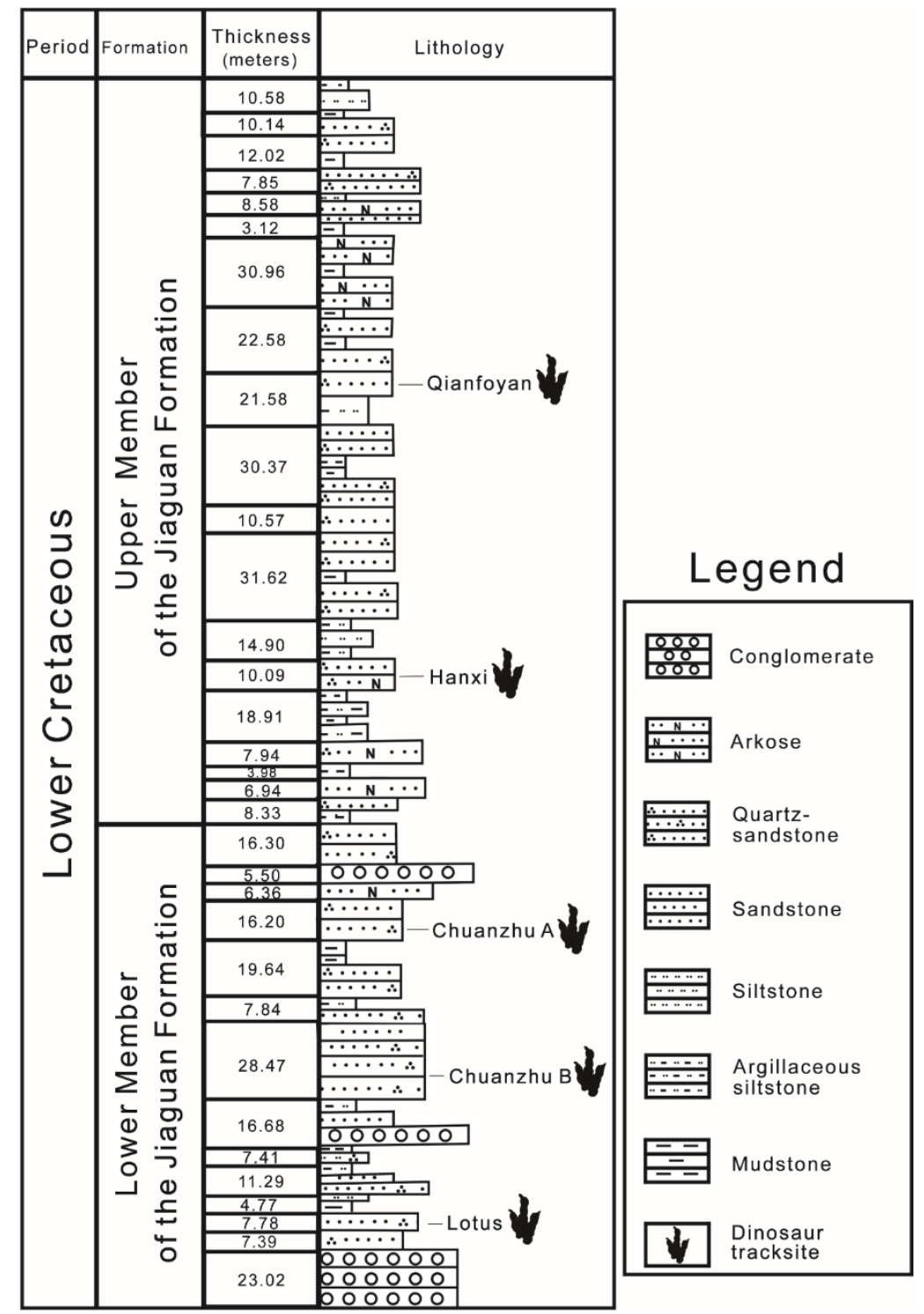

Figure 2. The lithostratigraphic section showing sediment characteristics and position of track-bearing levels at the Qianfoyan Site and other dinosaur track site from Jiaguan Formation. 


\section{Theropod tracks}

\subsection{Description}

The mean length and width of the LYD-T1-L1L2 tracks are $15.0 \mathrm{~cm}$ and $12.7 \mathrm{~cm}$, respectively, making the mean length/width ratio 1.2 (Table 1). LYD-T1 is the most well-preserved track in the Qianfoyan area (Figs 3, 7) and is a good morphological representative of all the LYD-T1L1-L2T1-L1 tracks. Digit III projects the farthest anteriorly, followed by digits II and IV. One round metatarophalangeal pad trace is present posterior to digit III. The digit pad impressions are indistinct. Each digit has a sharp claw mark, and digit II has the clearest and longest mark. The divarication angle between digit II and IV is relatively wide $\left(69^{\circ}\right)$. The divarication angle between digits II and III $\left(35^{\circ}\right)$ is almost the same as that between digits III and IV $\left(34^{\circ}\right)$. LYD-T1L1 has an apparent outward rotation: $\sim 21^{\circ}$ from the midline of the trackway. LYD-T1 is characterized by weak mesaxony (average 0.38 , range $0.26-0.49, \mathrm{~N}=3$ ). The step is 2.6 times larger than the footprint length. The pace angulation is $173^{\circ}$, making it a narrow trackway. The features of LYD-T1-R1 and L2 are basically similar to those of the T1-L1.

\begin{tabular}{r|ccccccccc}
\hline & $\mathrm{L}$ & $\mathrm{W}$ & $\mathrm{R}$ & $\mathrm{PL}$ & $\mathrm{SL}$ & $\mathrm{PA}$ & $\mathrm{L} / \mathrm{W}$ & $\mathrm{M}$ & $\mathrm{II}-\mathrm{IV}$ \\
\hline LYD-T1-L1 & 16.3 & 13.6 & 21 & 38.0 & 79.0 & 173.0 & 1.2 & 0.49 & 69 \\
LYD-T1-R1 & 15.5 & 12.5 & - & 41.0 & - & - & 1.2 & 0.26 & 52 \\
LYD-T1-L2 & 13.1 & 11.9 & - & - & - & - & 1.1 & 0.38 & 69 \\
Mean & 15.0 & 12.7 & 21 & 39.5 & 79.0 & 173.0 & 1.2 & 0.38 & 63 \\
LYD-TI1 & 13.8 & 8.7 & - & - & - & - & 1.6 & 0.54 & 50 \\
LYD-TI2 & 14.0 & 9.8 & - & - & - & - & 1.4 & 0.55 & 58 \\
LYD-TI3 & 11.0 & 8.3 & - & - & - & - & 1.3 & 0.55 & 65 \\
LYD-TI4 & 11.0 & - & - & - & - & - & - & - & - \\
LYD-TI5 & 22.4 & 17.7 & - & - & - & - & 1.3 & - & - \\
QFY-T1-L1 & 30.0 & 16.0 & - & 114.3 & - & - & 1.9 & 0.68 & 43 \\
QFY-T1-R1 & 24.0 & 18.0 & - & - & - & - & 1.3 & 0.39 & 54 \\
Mean & 27.0 & 17.0 & - & 114.3 & - & - & 1.6 & 0.53 & 49 \\
QFY-TI1 & 12.7 & 13.0 & - & - & - & - & 1.0 & 0.44 & 96 \\
QFY-TI2 & 12.0 & 7.5 & - & - & - & - & 1.6 & 0.47 & 46 \\
QFY-TI3 & 9.6 & 5.6 & - & - & - & - & 1.7 & 0.61 & 48 \\
QFY-TI4 & 13.4 & - & - & - & - & - & - & - & - \\
QFY-TI5 & 12.0 & 5.8 & - & - & - & - & 2.1 & 0.78 & 41 \\
QFY-TI6 & 10.8 & - & - & - & - & - & - & - & - \\
QFY-TI7 & 16.7 & 10.6 & - & - & - & - & 1.6 & 0.38 & 46 \\
QFY-TI8 & 15.0 & 11.9 & - & - & - & - & 1.3 & 0.54 & 71 \\
\hline
\end{tabular}

Table 1. Measurements (in centimeter, degree and square centimeter) of the theropod trackways from Lingyadong and Qianfoyan sites, Sichuan Province, China. Abbreviations: L: Maximum length; W: Maximum width; R: Rotation; PL: Pace length; SL: Stride length; PA: Pace angulation; $\mathrm{L} / \mathrm{W}$ is dimensionless; M: Mesaxony; II-IV: the divarication angle of digits II-IV. 


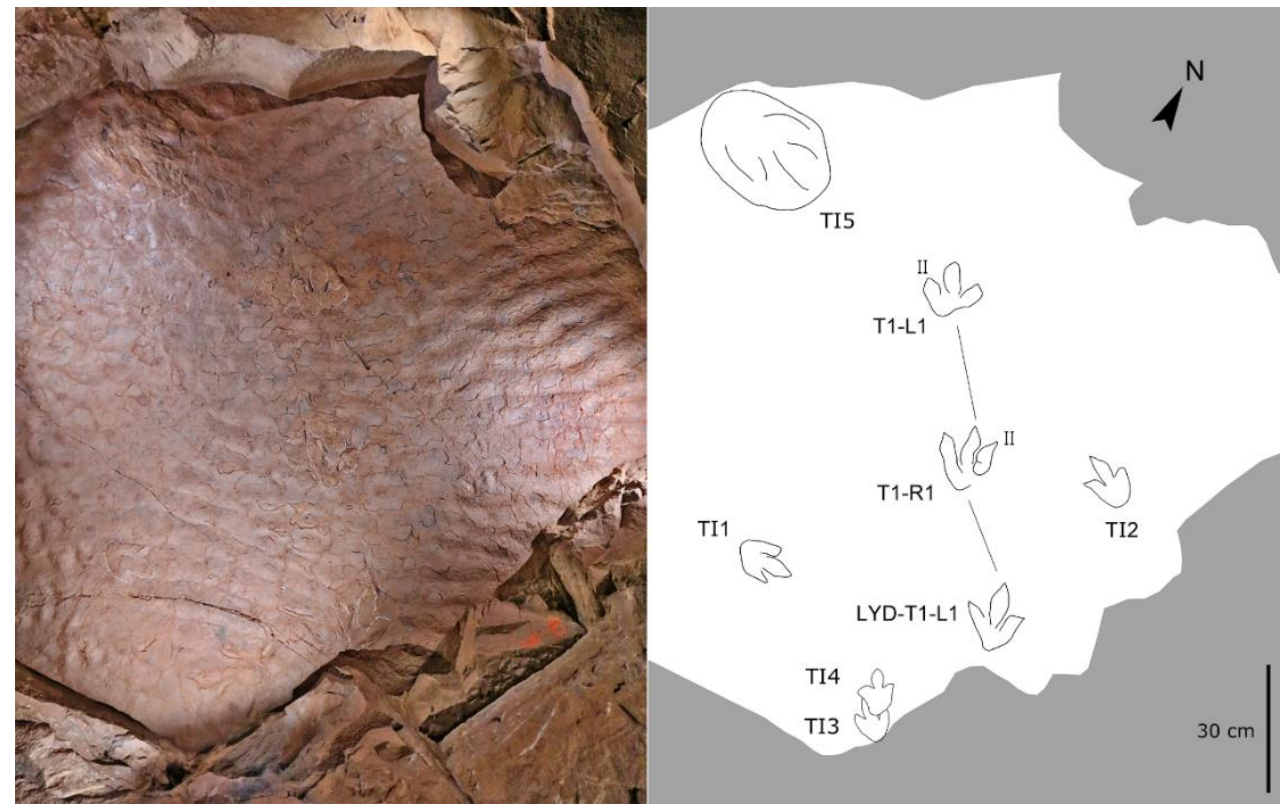

Figure 3. An overview photograph and line drawing of theropod tracks from Lingyadong Site.

The lengths of LYD-TI1 and TI2 are $13.8 \mathrm{~cm}$ and $14.0 \mathrm{~cm}$ and their length/width ratios are 1.6 and 1.4 , respectively. Both tracks have stronger mesaxony than LYD-T1, (0.54 and 0.55 , respectively). The divarication angles between digit II and IV are a bit narrower, $50^{\circ}$ and $58^{\circ}$, respectively. The digit pad impressions are faint. LYD-TI3 and TI4 are poorly preserved and are the smallest footprints in this track site. They are both $11 \mathrm{~cm}$ long, their length/width ratio is 1.3 (slightly lower than that of LYD-TI2), and their mesaxony is in accord with that of LYD-TI2. LYD-TI3 and TI4 have the same length and morphology, and may have been left by the same foot.

LYD-TI5 is located in an oval cast that measures $33.5 \mathrm{~cm}$ in length and $24.3 \mathrm{~cm}$ in width. Three faint digit impressions are discernable. The length of the footprint is $22.4 \mathrm{~cm}$, the width is $17.7 \mathrm{~cm}$, and the length/width ratio is 1.3. This makes LYD-TI5 the largest footprint at this site.

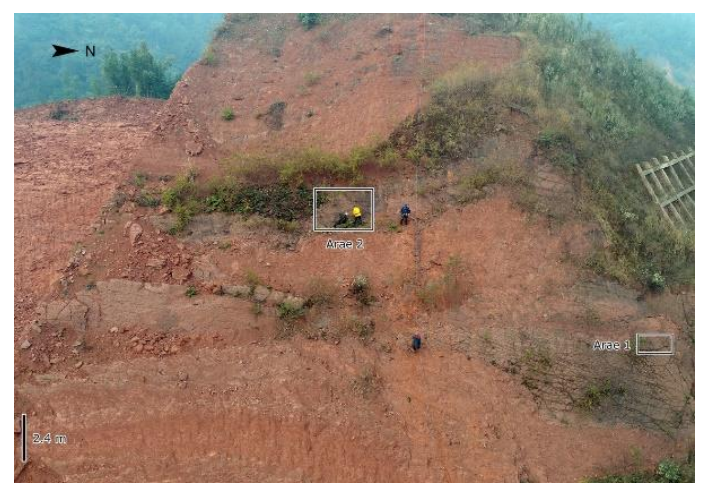

Figure 4. An overview photograph of Qianfoyan site.
QFY-T1-L1 and R1 are located at Qianfoyan Site Area 1(Fig 5). The mean length and width are $27.0 \mathrm{~cm}$ and $17.0 \mathrm{~cm}$, respectively. The mean length/width ratio is 1.6. Digit III projects the farthest anteriorly, followed by digits II and IV. One round metatarophalangeal pad trace is present posterior to digit III. The digit pad impressions are indistinct. Each digit has a sharp claw mark, and digit III has the clearest and longest mark. The divarication angles between digit II and IV are relatively narrow $\left(49^{\circ}\right)$. QFY$\mathrm{T} 1$ is characterized by weak mesaxony (average 0.53 ). The step is more than 4.2 times longer than footprint length.

QFY-T1-L1 and R1 are located in Qianfoyan Site Area 1. The mean length and width are $27.0 \mathrm{~cm}$ and $17.0 \mathrm{~cm}$, respectively. The mean length/width ratio is 1.6. Digit III projects the farthest anteriorly, followed by digits II and IV. One round metatarophalangeal pad trace is present posterior to digit III.

The digit pad impressions are indistinct. Each digit has a sharp claw mark, and digit III has the clearest and longest mark. The divarication angles between digit II and IV are relatively narrow $\left(49^{\circ}\right)$. QFY-T1 is characterized by weak mesaxony (average 0.53 ). The step is more than 4.2 times the footprint length.

QFY-TI1-8 are located in Qianfoyan Site Area 2 (Figs 6, 8). QFY-TI1-6 are orientated from south to north, and QFY-TI7 and TI8 from east to west. None of the footprints clearly belong to trackways, but TI3 and TI6 may form a single step. QFYTI1 -8 are variable in overall size and proportions, 
ranging from 9.6 to $16.7 \mathrm{~cm}$ in length, with a length/width ratio ranging from 1.3 to $2.1 \mathrm{~cm}$, and mesaxony ranging from 0.38 to 0.78 . The best preserved of these is QFY-TI8. QFY-TI8 has a length of $15.0 \mathrm{~cm}$, a width of $11.9 \mathrm{~cm}$, and a length/width ratio of 1.3 . It has a single round metatarophalangeal pad trace posterior to digit III. No digital pad traces are visible across much of the track, because they are covered by overlaying sediments. Digit III has a sharp claw mark. The divarication angle between digit II and IV is relatively wide $\left(71^{\circ}\right)$ and digits II and IV show weak mesaxony $(0.54)$.

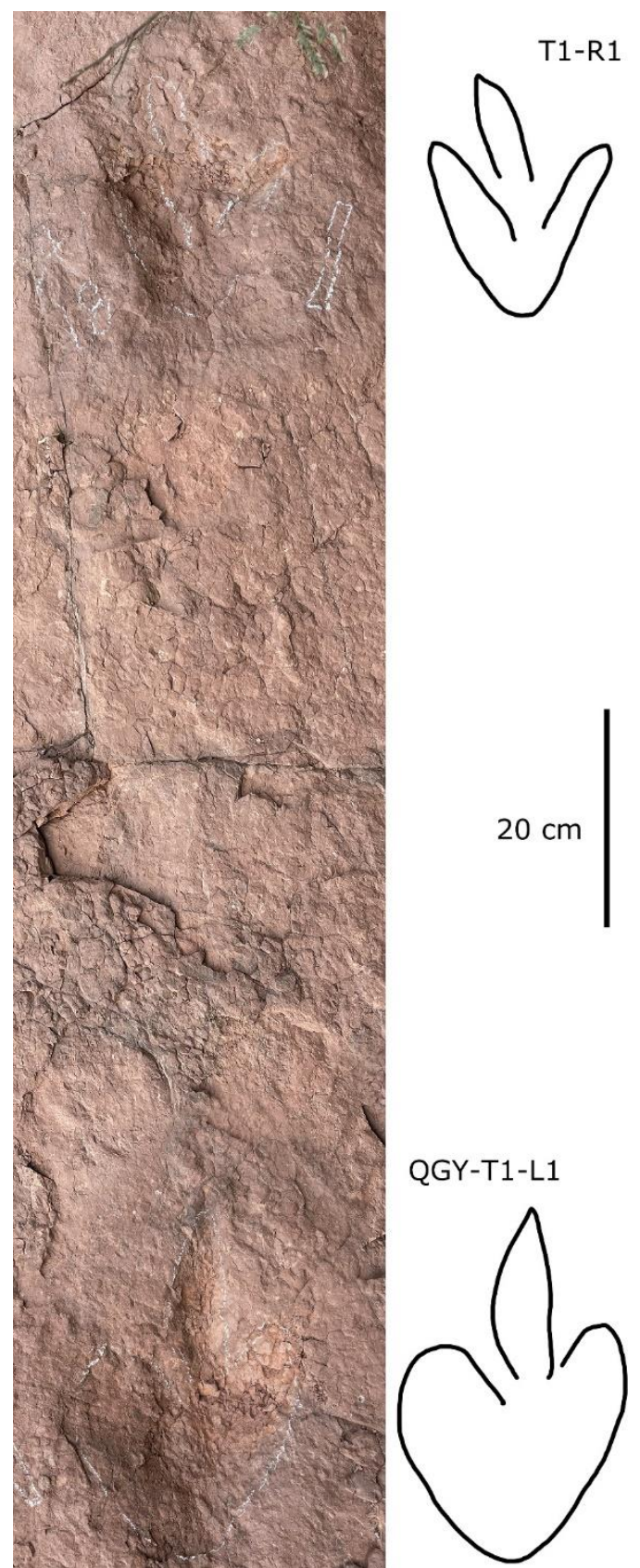

Figure 5. Photograph and line drawing of theropod track step from Qianfoyan Site.
QFY-TI5 shows a distinct morphology. It is 12.0 $\mathrm{cm}$ long and $5.8 \mathrm{~cm}$ wide, with a length/width ratio of 2.1. There is one round metatarophalangeal pad trace posterior to digit III, but there are no distinct digital pad traces. Digit III has a sharp claw mark. The digits have strong mesaxony (0.78) and the divarication angle between digit II and IV is narrow $\left(41^{\circ}\right)$.

\subsection{Comparison and discussion}

\section{Paracorpulentapus}

LYD-T1 from the Lower Cretaceous Jiaguan Formation is superficially similar to the theropod ichnogenus Paracorpulentapus from the Upper Cretaceous Xiaoyan Formation. However, the sub-optimal quality of preservation does not permit confident identification of the tracks at the ichnogenus level. Xing et al. (2014) named Paracorpulentapus zhangsanfengi recognizing it to be larger than Corpulentapus (Li et al., 2011) in absolute size (16 cm vs. $11.8 \mathrm{~cm})$, having slightly stronger mesaxony $(0.37>0.32)$, and wider divarication $\left(74^{\circ}>65^{\circ}\right)$. Paracorpulentapus has the following characteristics: it is a robust tridactyl theropod tracks, almost as wide as it is long, it is mediumsize $(\sim 16.0 \mathrm{~cm}$ long and $\sim 15.4 \mathrm{~cm}$ wide); it has a mean divarication between digits II and IV of $74^{\circ}$; it has weak mesaxony; the digit traces are relatively short and "fleshy" with blunt claws and only indistinct creases between pads; the digits traces are separated by a hypex for most of their proximal length; digit IV is always the narrowest; digit traces II and III proximally with thin interspace area; the metatarsophalangeal pad of digit IV is close to the axis of digit III and forms a short rounded "heel"; the trackways are narrow with short steps; step lengths are 2.7 times that of the track length. The LYD-T1 trackway conforms to or closely resembles most of these features: the tracks are medium-sized $(15 \mathrm{~cm})$ robust tridactyl theropod tracks, with and average length/width ratio of 1.2 , the average divarication between digits II and IV is $63^{\circ}\left(52^{\circ}-69^{\circ}\right)$, the average mesaxony is weak $(0.38)$, the average step length is 2.6 times that of the average footprint length. Thus, we tentatively label trackway LYD-T1 as $P$. zhangsanfengi. Among the isolated tracks, the morphology of QFY-TI8 is similar to $P$. zhangsanfengi, but QFY-TI8 has a much higher mesaxony (0.54). 


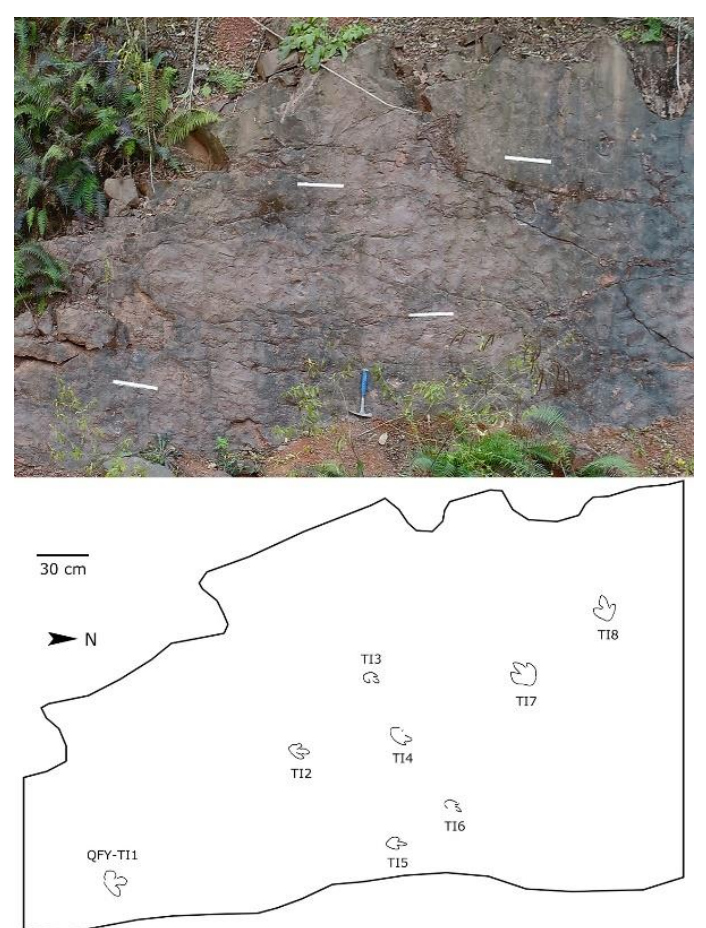

Figure 6. Photograph and line drawing of the distribution of theropod tracks from Qianfoyan Site.

Trackmaker speed (v) was calculated using Alexander's (1976) formula: $\mathrm{v}=0.25 \mathrm{~g}^{0.5}$. SL ${ }^{1.67}$. $\mathrm{h}^{-1.17}$, where $\mathrm{g}=$ gravitational acceleration in $\mathrm{m} / \mathrm{sec}$; SL = stride length; and $\mathrm{h}=$ hip height, estimated as 4.9 times foot length, using the ratio for small theropods proposed by Thulborn (1990). Based on the length of the stride of LYD-T1, we estimate a speed of $\sim 0.84 \mathrm{~m} / \mathrm{s}$ or $\sim 3.02 \mathrm{~km} / \mathrm{h}$. The relative stride length $(\mathrm{SL} / \mathrm{h})$ is 1.17 , implying that the animal was walking, not trotting or running. This state is also similar to the SL/h value (1.2) of $P$. hangsanfengi.

\section{Small Eubrontid track}

The length of LYD-TI-TI4 is only $11.0-14.0 \mathrm{~cm}$, the length/width ratio is 1.3-1.6, and characterized by weak to moderate mesaxony (range 0.54-0.55), which is typical for footprints of the ichno- or morphofamily Eubrontidae (Lockley, 2009). However, LYD-TI-TI4 commonly have a wider divarication of digits IIIV $\left(50^{\circ}-65^{\circ}\right)$ compared with the North American Eubrontes from the Late Triassic-Early Jurassic $\left(10^{\circ}-40^{\circ}\right.$; Olsen et al., 1998).

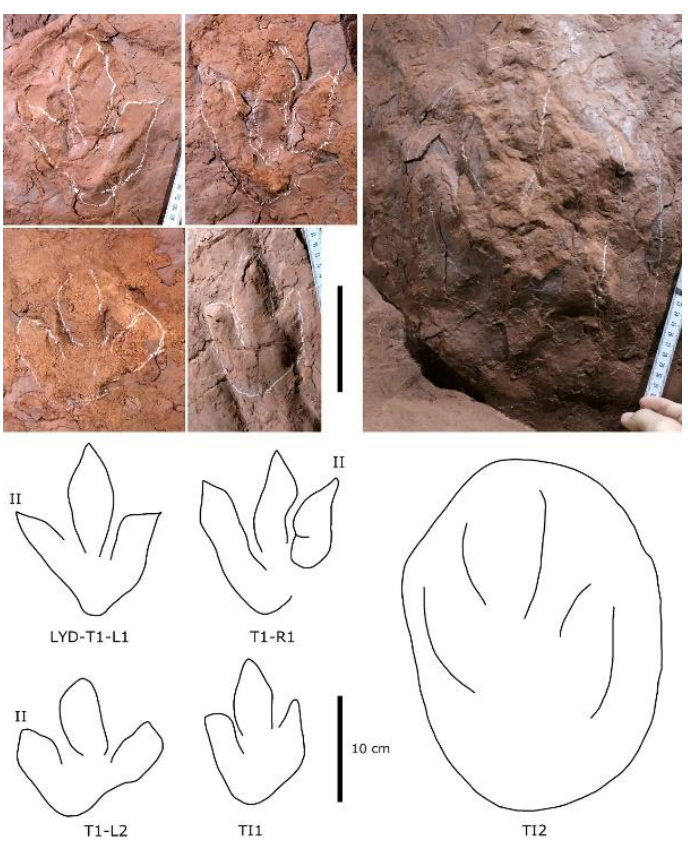

Figure 7. Photograph and line drawing of theropod tracks from Lingyadong Site.

\section{Eubrontid tracks}

QFY-T1-L1 and R1 have a mean length of $27 \mathrm{~cm}$ and a length/width ratio of 1.6. Both are characterized by weak to moderate mesaxony (average0.53). These proportions are typical for footprints of the ichno- or morphofamily Eubrontidae (Lockley, 2009). Similar tracks abound in the Chinese Jurassic and Cretaceous track record (Lockley et al., 2013; Xing et al., 2016). Although the small sample size and limited preservation state makes the identification of specific systematic features difficult, these tracks are here classified as eubrontid tracks. QFY-T1L1 and R1 constitute a single step. Assuming that the length of a stride equals that of two steps, speed was calculated using Alexander's (1976) formula, estimated as 4.9 times foot length, using the ratio for large theropods proposed by Thulborn (1990). We estimate a speed of $\sim 2.24$ $\mathrm{m} / \mathrm{s}$ or $\sim 8.06 \mathrm{~km} / \mathrm{h}$. The relative stride length $(\mathrm{SL} / \mathrm{h})$ is 1.73 , implying that the animal was walking, not trotting or running.

\section{Grallatorid tracks}

QFY-TI5 has a high length/width ratio (2.1), strong mesaxony (0.78), and resemble grallatorid tracks (Lockley, 2009). Similar footprints are found in abundance in the Jurassic-Cretaceous boundary and Early Cretaceous records of China. For example, Morphotype B grallatorid tracks from Yanqing, Beijing have a length/width ratio and mesaxony of 0.89 and 2.0, respectively (Xing et al., 2015). Although, the mesaxony is weaker than that reported for North American Grallator 
(Olsen et al., 1998; Lockley, 2009). The small sample size makes it difficult to identify systematic features, but QFY-TI5 herein tentatively referred to grallatorid tracks.

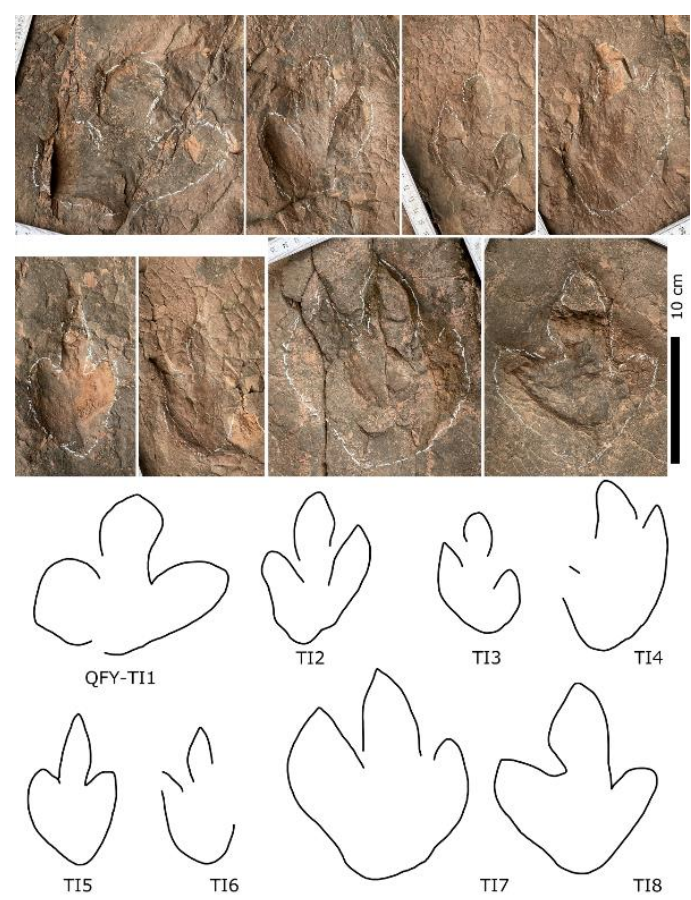

Figure 8. Photograph and line drawing of theropod tracks from Qianfoyan Site.

\section{Discussion}

The Upper Cretaceous Xiaoyan Formation Xiaohutian site of Huangshan City, Anhui Province, has a theropod tracks assemblage that includes Paracorpulentapus, Therangospodus, and small eubrontid tracks (Xing et al., 2014). That theropod ichnotaxa fauna is very similar to that of the Qianfoyan sites. Sullivan (2006) tentatively assigned the Xiaoyan Formation to the early Maastrichtian, based on the pachycephalosaurid record. Paracorpulentapus from the Qianfoyan sites is the first record of the genus in the Early Cretaceous (Jiaguan Formation, Barremian-Albian). Xing et al. (2014) mentioned that the theropod trackmaker of the Paracorpulentapus may have been a short toed and long legged theropod. Qianfoyan sites in the southwestern China is separated from the Xiaohutian site by a relatively large time span and geographical distance (it is roughly $1400 \mathrm{~km}$ east). However, both sites are at a similar latitude: $29^{\circ} 48^{\prime} \mathrm{N}$ (Xiaohutian tracksite) and $29^{\circ} 45^{\prime} \mathrm{N}$ (Qianfoyan area). The Jiaguan deposition was located at $25.5^{\circ}$ ancient north latitude (Jiang et al., 2000). The sedimentary environments of both are also similar. The Xiaohutian tracks are also preserved in the red sandstone of fluviallacustrine facies (Xing et al., 2014).
The theropod track assemblages from the Jiaguan Formation not only consisted of the classic Grallator and Eubrontes assemblages but also Dromaeopodus, Velociraptorichnus, and Minisauripus (Xing \& Lockley, 2016). Lockley et al. (2014) suggested that the composition of China's Early Cretaceous ichnofaunas implies a distinctive regional signature. The record of Paracorpulentapus also fits in this situation. Like other track sites in the Lower Cretaceous Jiaguan Formation, the theropod track assemblages in Qianfoyan area, Paracorpulentapus, small and larger eubrontid, grallatorid tracks together suggest a relatively high diversity.

\section{Conclusion}

The dinosaur tracks from the upper part of the Jiaguan Formation in the Tang Dynasty Grottoes area are preserved in unusual situations, in the Lingya cave and on a steep rock face at the Qianfoyan site. The assemblages together yield 18 footprints and represent the $20^{\text {th }}$ and $21^{\text {st }}$ reported from the Jiaguan Formation, and are completely theropod-dominated like several others from this formation.

\section{Acknowledgments}

This research was funded by the National Natural Science Foundation of China (No. 41772008, 41772023).

\section{References}

Alexander R. (1976). Estimates of speeds of dinosaurs. Nature, 261, 129-130. https://doi.org/10.1038/261129a0

Chen, H.X. (2009). Research of Paleoenvironment and Paleoclimate of Cretaceous in Ya'an Area of Western Sichuan Basin. Master Thesis (pp. 86). Chengdu: Chengdu University of Technology, China press.

Geng, Q. (2011). Tectonic sequence stratigraphy and lithofacies paleogeography of Cretaceous-Paleogene in Sichuan Basin of China. Journal of Chengdu University of Technology Science \& Technology Edition, 38 (4), 394-401.

Gu, X.D., \& Liu, X.H. (1997). Stratigraphy (Lithostratic) of Sichuan Province. Wuhan: China University of Geosciences Press; p. 417 in Chinese.

He, FL. (2010). Main problems and countermeasures on grotto and stature on cliff, Sichuan, China. Journal of Engineering Geology, 18(S1), 450-454.

Jiang, X.S., Pan, Z.X., \&Fu, Q.P. (2000). The pattern of general atmospheric circulation in 
eastern Asia through Cretaceous. Sci China Ser D Earth Sci, 30, 587-591.

Leonardi, G., 1987. Glossary and manual of tetrapod footprint palaeoichnology. Departamento Nacional de Producão Mineral; p.75 in Brazil.

Li, R., Lockley, M.G., Matsukawa, M., Wang, K., \& Liu, M. (2011). An unusual theropod track assemblage from the Cretaceous of the Zhucheng area, Shandong Province, China. Cretaceous Research, 32, 422-432. https://doi.org/10.1016/j.cretres.2010.10.00 $\underline{6}$

Liang, S.C. (2011). A History of Chinese Architecture (pp. 329). Beijing: SDX Joint Publishing.

Lockley, M.G. (2009). New perspectives on morphological variation in tridactyl footprints: clues to widespread convergence in developmental dynamics. Geological Quarterly 53, 415-432.

Lockley, M.G., \& Hunt, A.P. (1995). Dinosaur tracks and other fossil footprints of the western United States (pp. 360). New York: Columbia University Press.

Lockley, M.G., Li, J.J., Li, R.H., Matsukawa, M., Harris, J.D.\& Xing, L.D. (2013). A review of the tetrapod track record in China, with special reference to type ichnospecies: implications for ichnotaxonomy and paleobiology. Acta Geologica Sinica (English edition), 87(1), 1-20. https://doi.org/10.1111/1755-6724.12026

Lockley, M.G., Xing, L.D., Kim, J.Y.\& Matsukawa, M. (2014). Tracking Early Cretaceous Dinosaurs in China: a new database for comparison with ichnofaunal data from Korea, the Americas, Europe, Africa and Australia. Biological Journal of the Linnean Society, 113, 770-789. https://doi.org/10.1111/bij.12308

National Administration of Cultural Heritage (2009). The atlases of Cultural Relics, China, Sichuan fascicule (pp.1854). Beijing Cultural Relics Publishing.

Olsen, P. E., Smith, J.B.\& McDonald, N.C. (1998). Type material of the type species of the classic theropod footprint genera Eubrontes, Anchisauripus and Grallator (Early Jurassic, Hartford and Deerfield Basins, Connecticut and Massachusetts, U.S.A.). Journal of Vertebrate Paleontology, 18(3), 586-601. https://doi.org/10.1080/02724634.1998.100 11086

Sichuan Provincial Bureau of Geology aviation regional Geological Survey team (1976). Geological Map of the People's Republic of China, Xuyong Map Sheet 1:200000 (H-48XXXIV).
Sullivan, R.M. (2006). A taxonomic review of the Pachycephalosauridae (Dinosauria: Ornithischia). New Mexico Museum of Natural History and Science Bulletin, 35, 347-365.

Thulborn, T., 1990. Dinosaur Tracks. London: Chapman \& Hall.

Xing, L.D.\& Lockley, M.G. (2016). Early Cretaceous dinosaur and other tetrapod tracks of southwestern China. Science Bulletin, 61(13), 1044-1051. https://doi.org/10.1007/s11434-016-1093-Z

Xing, L.D., Lockley, M.G.\& Zhang, J.P. (2016). Early Cretaceous dinosaur and other tetrapod tracks of southwestern China. Ningbo: Ningbo Publishing House.

Xing, L.D., Lockley, M.G., Zhang, J.P., Klein, H., Kim, J.Y., Persons, W.S.IV., Matsukawa, M., Yu, X.Q., Li, J.J., Chen, G.B.\& Hu, Y. (2014). Upper Cretaceous dinosaur track assemblages and a new theropod ichnotaxon from Anhui Province, eastern China. Cretaceous Research, 49, 190-204. https://doi.org/10.1016/j.cretres.2014.03.00 $\underline{3}$

Xing, L.D., Zhang, J.P., Lockley, M.G., McCrea, R.T., Klein, H., Alcalá, L., Buckley, L.G., Burns, M.E., Kümmell, S.B.\& He, Q. (2015) Hints of the early Jehol Biota: important dinosaur footprint assemblages from the Jurassic-Cretaceous Boundary Tuchengzi Formation in Beijing, China. PLOS ONE, 10(4): $\quad$ e0122715. https://doi.org/10.1371/journal.pone.01227 $\underline{15}$

Xing, L.D., Lockley, M.G., Klein, H., Zeng, R., Cai, S.F., Luo, X.C.\& Li, C. (2018a). Theropod assemblages and a new ichnotaxon Gigandipus chiappei ichnosp. nov. from the Jiaguan Formation, Lower Cretaceous of Guizhou Province, China. Geoscience Frontiers, 9, 1745-1754. https://doi.org/10.1016/j.gsf.2017.12.012

Xing, L.D., Dai, H., Lockley, M.G., Romilio, A., Klein, H., Li, Z.D., Hu, X.F., Peng, G.Z., Ye, Y.\& Persons, W.S.IV. (2018b). Two new dinosaur tracksites from the Lower Cretaceous Jiaguan Formation of Sichuan Basin, China: specific preservation and ichnotaxonomy. Historical Biology ,30:7, 976-984.

https://doi.org/10.1080/08912963.2017.132 $\underline{6113}$

Xing, L.D., Lockley, M.G., Klein, H., Zhang, L.J., Romilio, A., Persons, W.S.IV., Peng, G.Z., Ye, Y.\& Wang, M.Y. (In review). The new ichnotaxon Eubrontes nobitai ichnosp. nov. and other Saurischian tracks from the Lower Cretaceous Sichuan Province and a review of Chinese Eubrontes type tracks. Journal of 


\section{Palaeogeography.}

Yu, C.\& Wang, T. (2012). Cliff of Thousand Buddhas: Investigation Report of Ancient

Cliff Statues in Jiajiang, Sichuan Province (pp.199). Beijing: Cultural Relics Press.

\section{(c) $\underset{B Y}{(} \bigodot_{\mathrm{ND}}$} jurisdictional claims in published maps and institutional affiliations.

Open Access This article is licensed under a Creative Commons Attribution-NoDerivatives 4.0 International (CC BY-ND 4.0) licence, which permits copy and redistribute the material in any medium or format for any purpose, even commercially. The licensor cannot revoke these freedoms as long as you follow the licence terms. Under the following terms you must give appropriate credit, provide a link to the license, and indicate if changes were made. You may do so in any reasonable manner, but not in any way that suggests the licensor endorsed you or your use. If you remix, transform, or build upon the material, you may not distribute the modified material.

To view a copy of this license, visit https://creativecommons.org/licenses/by-nd/4.0/. 